\title{
The Vatican Observatory Summer Schools in Observational Astronomy and Astrophysics
}

\author{
Christopher J. Corbally \\ Vatican Observatory, University of Arizona, Tucson AZ 85721, U.S.A. \\ e-mail: corbally@as.arizona.edu
}

\begin{abstract}
Two seemingly incongruous components have come together about every two years: the serene terraces of the Pope's summer residence at Castel Gandolfo, and the noisy exuberance of 25 beginning-level graduate students. Add in a small faculty of first-rate professors and a resourceful local support team, and one has the ingredients for the month-long Vatican Observatory Summer Schools. The eighth School takes place in the summer of 2001, and its goals are the same as when the series started in 1986: to encourage and motivate a mix of young people from industrialized and developing countries who are at critical moments of their research careers, and to make a small, but significant contribution to the progress of developing countries by exposing some of their most talented young citizens to people involved in high quality research in astrophysics. This account outlines the nature of the Schools, their follow-up, and something of how the spirit of sharing of personal and institutional resources is achieved.
\end{abstract}

\section{Introduction}

It certainly can seem an odd combination to the students who apply: the Vatican hosting a Summer School in astronomy. Will they be expected to spend as much of their days at the School in church as in the classroom? My sense is that the students do find our Vatican Observatory Summer Schools unique, but not in the way they might have thought initially.

The uniqueness stems from the way in which the idea was conceived. Martin McCarthy, now retired from the Vatican Observatory, was pacing on the upper terrace of Castel Gandolfo during a night in 1984 before one of his departures back to the United States. He was musing about our fruitful exchanges with colleagues, both those that happened at observatories or at formal meetings, sometimes run by the Vatican. But what more could we do to help make the wonders of the heavens better understood and appreciated? Then came the inspiration: share our facilities at Castel Gandolfo with talented younger scientists, from both industrialized and developing nations. From this start the Vatican Observatory Summer Schools (VOSS, for short) took initial shape in his mind.

The shape was refined when McCarthy discussed the idea with George Coyne, the director, on the way to Fiumicino airport the following morning. 
As Coyne would emphasize to the Vatican authorities, the Vatican Observatory was not aspiring to become a teaching institute but, by running a Summer School about every other year, wanted to encourage and motivate a mix of young people from industrialized and developing countries who were at critical moments of their research careers. In addition, the School's hope was to make a small, but significant contribution to the progress of developing countries by exposing some of their most talented young citizens to people involved in high quality research in astrophysics.

So, this was to be a School in which a mutual sharing would benefit astronomy in all nations, even while significantly impacting developing nations. If this mix was to happen, then about two-thirds of the students at the School would have to be substantially financed. The Vatican authorities supported the idea and preparations for the first School, held in 1986, started.

\section{Short Description}

From our goals it follows that for each School we try to choose 25 students, coming from all over the world, who are at an early graduate level, and who show ability and real passion for astrophysical research (a broad term to include all the branches of astronomy, theoretical and observational). Our website (http://clavius.as.arizona.edu/vo/voss.html) links to the current announcement and application details. You will see there that we put a great deal of weight on the brief statement given by each applicant on why they wish to attend a School. We also much rely on the two letters of reference to distinguish applicants who are highly motivated towards research from those who are merely brilliant in their studies.

The academic structure of the VOSS is quite simple. The topic is chosen by the dean and the director. These two, to complement our Vatican Observatory's staff, seek a small faculty from people who are actively engaged in astrophysical research in that topic, who are renowned in the international community of scholars, and who are good communicators of the passion they have for their work (Table 1). (Note that the topic and faculty are limited. In this way the subject is treated at depth and the relationships between students and faculty can become relaxed.) The Schools last one month, ending before the Pope's official summer visit to Castel Gandolfo in mid-July. The daily pattern has evolved into two substantial lectures on the School's topic being given in the morning, Monday to Friday, and presentations by the students or guest lecturers following these immediately before lunch. Guest lectures broaden the scope of the School. One such lecture focussed on working with media, a vital way to harmonize the seemingly opposing needs in a developing country of fostering national pride and of accepting foreign collaborations (a problem raised by $R$. $\mathrm{K}$. Kochhar in the panel discussion that ended this Special Session -see pp. 367-370).

Our intent for the Schools is serious, to help young scientists develop research careers in astrophysics, but the secret of achieving this is that, above all, we should all have fun at the Schools. The learning is fun, even in class. We are learning purely for the sake of learning and not for any examination results. A certificate of successful attendance is all that the students take home. That 
Table 1. VOSS Faculty and Themes

\begin{tabular}{|c|c|c|c|}
\hline Year & $\operatorname{Dean}(\mathrm{s})$ & Faculty ${ }^{I}$ & Theme(s) \\
\hline 1986 & M.McCarthy & D.Latham, V.Rubin & Stars and Galaxies \\
\hline 1988 & $\begin{array}{l}\text { C.Corbally } \\
\text { \& C.Lada }\end{array}$ & J.Goad/Keppel, F.Shu & $\begin{array}{l}\text { Star Formation } \\
\text { and Galaxies }\end{array}$ \\
\hline 1990 & C.Corbally & $\begin{array}{l}\text { R.Garrison, J.Stocke, } \\
\text { J.Van Gorkam }\end{array}$ & $\begin{array}{l}\text { Stellar Spectroscopy } \\
\text { and Galaxies }\end{array}$ \\
\hline 1993 & R.Boyle & $\begin{array}{l}\text { P.Biermann, G.Rieke, } \\
\text { M.Rieke }\end{array}$ & Activity in Galaxies \\
\hline 1995 & W.Stoeger & C.Frenk, C.Impey & Cosmology \\
\hline 1997 & G.Consolmagno & $\begin{array}{l}\text { M.A'Hearn, H.Campins, } \\
\text { F.Vilas }\end{array}$ & $\begin{array}{l}\text { Comets, Asteroids } \\
\text { and Meteorites }\end{array}$ \\
\hline 1999 & C.Corbally & $\begin{array}{l}\text { R.Gray, M.Richards, } \\
\text { R.Kudritzki }\end{array}$ & $\begin{array}{l}\text { Single Stars } \\
\text { and Close Binaries }\end{array}$ \\
\hline 2001 & G.Coyne & $\begin{array}{l}\text { G.Schmidt, R.Narayan, } \\
\text { W.Stoeger, F.D'Antona }\end{array}$ & Stellar Remnants \\
\hline
\end{tabular}

${ }^{1}$ The regular faculty are often assisted by other senior scientists in residence. Notable among these have been Emmanuel Carreira, S.J., and Vilppu Piirola.

makes for a totally different classroom situation from what is dictated back in home institutions. It is one where "egos are left at Fiumicino airport upon arrival," in the words of one of the faculty. No question is stupid, and no question is asked to show the superior knowledge of the questioner or to put the professor on the spot. This is a unique opportunity to probe foundations.. "I was asked questions for which I did not know I had the answers," was the typical experience of another of our faculty. Yes, we all (re-)learn that teaching and learning can be fun.

Meeting people coming from different countries and situations is obviously fun too, once initial apprehension or shyness is overcome. Castel Gandolfo's situation in Italy gives us a rich cultural context in which to have those encounters take place. There is a "free lunch" for all on the terrace overlooking Lake Albano after the morning's lectures. The afternoons are free to siesta, to study, to play soccer, to swim in the lake, to visit Rome, etc. Most evenings are free also, though the students might arrange a party featuring a national cuisine, a formal discussion, or some stargazing through our rooftop telescopes -no longer really used for research observing, but Mattei and Percy (2001) suggest a way of doing useful science with them. Encounters with each other and with different cultures are the themes of outings at the weekend. These are generally organized for the Saturday only, but the central weekend is devoted to an overnight trip for everyone, funded by the School, to a place of astronomical and cultural interest such as Florence.

Amid all this fun is there serious study too? From what I have seen of individuals and groups around the Papal Palace hard at work on projects, the answer is a definite, "yes." We encourage the students to work in groups for several reasons: it extends our resources such as computers and library, it promotes interactions, and it helps the English-language skills of the students. Overcom- 
ing the English-language barrier, as Mahoney (2001) well points out, is a major problem for some aspiring astronomers in developing countries. With this in mind, our Schools are run in English, but with help, and cheerful misunderstandings, available in other languages. Each student has to give at least one short talk to the whole School. For some this is a major undertaking, but it is a talk given to a supportive audience (who know what it feels like themselves) and so it can be a great help in breaking through the language barrier.

For those interested in further details, Joson \& Aguirre (2000) provide a recent description and pictures of the Schools.

\section{Follow-up}

The students feel that the Schools are all too short. Castel Gandolfo has become a second home to them. The end comes into sight just as they are really enjoying the science and the new friendships and are becoming more at ease with English. (The faculty have a slightly different perspective since day after day lectures, with many questions and interactions in and out of lecture time, are quite exhausting.) It is in that feeling of wanting to continue that one of the keys to a successful School is developed: follow-up.

The follow-up is first started among the students themselves as current addresses are exchanged. E-mail has obviously made a great difference, since the Schools began in 1986, to the ease of follow-up contacts (and to organizing the Schools in the first place), but it is heartening to find how much ordinary mail has been used among our alumni(ae) when necessary. Something of the "ThirdWorld networking", which Narlikar (2001) discusses as being so necessary, starts as the School itself ends.

Moreover, the students have also made friends with the invited faculty and with the staff of the Vatican Observatory, and contacts at all levels continue. Such contacts are vital for placing some of our alumni in graduate schools that will suit their talents and enthusiasm for astronomy. We have had many former VOSS students come to the University of Arizona, partly due to a scholarship from the Jesuit Community of the Vatican Observatory, now called the Martin F. McCarthy scholarship in honor of VOSS's inaugural dean. The HarvardSmithsonian Center, the Max Planck Institute, Bonn, and the University of Toronto are prominent in showing a similar welcome. All the faculty and deans, and especially Coyne as director, have written many effective letters of recommendation to help place alumni elsewhere. For, though there are no exams in the Schools, one can get to know a student's ability and potential very thoroughly over the course of a month through questions asked, general conversations made, and projects completed.

I am always glad to hear of and to experience times when VOSS alumni meet again at conferences. There the bond of friendship is renewed. So it was wonderful that, with the hard work of Chris Impey (faculty in 1995) and others, alumni from the first six Schools returned to Castel Gandolfo in June 1998 for a week-long International Symposium on Astrophysics Research and Science Education. Impey (1999) points out in the introduction to the meeting's proceedings that it soon acquired the appropriate nickname: Super-VOSS. It was unfashionably broad in its sweep of topics, reflecting the many research interests of the 
alumni, and refreshingly inspirational, both on the progress of astrophysics and on the challenge of educating in science, particularly in developing countries. It also accelerated Third-World networking. For once the alumni of each year had met and exchanged news among themselves (horizontal networking), I noticed how the groupings then became more those of continents, thus linking all the different VOSS years (vertical networking). In this way resources became pooled, at least potentially, to tackle common problems, whether scientific or educational.

There is one further thought concerning follow-ups to a School. Hearnshaw's (2001) "critical factors" for success of research in developing countries ring true in pointing to the contrast facing young researchers between the abundance they may have experienced in their graduate days and the relative isolation and lack they have awaiting them at their home institutions. With this in mind, the Vatican Observatory Foundation is raising funds to endow two post-doctoral fellowships at the University of Arizona. Through these fellowships we hope to help those from developing countries, such as our alumni, complete their training in astronomy in a stimulating environment and one where they can forge suitable, lasting collaborations for when they return to their own countries. We also want to take steps to ensure that their access to prime observing facilities and to stimulating meetings continues even when back home. Post-doctoral programs such as outlined would partly address Snowden's (2001) point on the lack of motivation among scientists in developing countries. The contrast is a problem, but every bit of collaboration helps to overcome it, as the success story of astronomy in Venezuela witnesses (Rosenzweig 2001).

\section{Impact}

Impact can be hard to assess adequately. The numbers are that in seven Vatican Observatory Summer Schools we have had 173 students from 48 different nations, with $57 \%$ of the students from developing nations. Table 2 gives the breakdown by continent and nations. (The cover devised by Chris Impey and Dana Irvin for the Super-VOSS proceedings - Impey 1999 - more dramatically shows the Schools' world coverage.) All but 10 alumni(ae) are either following professional careers in astrophysics or preparing to do so. Half of those from developing countries have spent at least two years with graduate programs or in research at leading institutes in industrialized nations. So the numbers tell of success in helping young scientists, including a good number from developing nations, to develop research careers.

Somehow though, on reading the accounts of faculty and alumni in The First Ten Years (Maggio 1997), it becomes clear that the impact of the Summer Schools is more to be measured by each person's growth into a more complete, more productive, more integrated researcher. Our alumni have come to realize that the friendships forged between all participants, students and faculty, are not an optional extra to success in research and teaching; they are the means to make research and teaching more productive because more human. These relationships are not meant to be exclusive; other colleagues are included as the years go by. It is such open-ended, professional, cross-cultural friendships 
Table 2. VOSS Distribution up to 1999 by Continents and Nations

\begin{tabular}{llc}
\hline Continent & Nation & Total \\
\hline AFRICA: & Nigeria 4, South Africa 5 & 9 \\
NORTH AMERICA: & Canada 8, Cuba 1, Mexico 4, & 29 \\
& United States 16 & \\
SOUTH AMERICA: & Argentina 14, Brazil 9, Chile 2, & \\
& Colombia 1, Peru 1, Uruguay 1, & \\
& Venezuela 6 & 34 \\
& China 5, India 9, Indonesia 1, & \\
ASIA: & Japan 1, Korea 3, Sri Lanka 4, & 26 \\
& Taiwan 2, Vietnam 1 \\
EAST EUROPE: & Armenia 1, Bulgaria 5, Croatia 4, & \\
& Estonia 2, Hungary 1, Iran 1, & \\
& Lithuania 1, Poland 5, Romania 1, \\
& Russia 3, Slovenia 1, Ukraine 5 & 30 \\
WEST EUROPE: & Austria 2, Belgium 2, Denmark 2, & \\
& Finland 4, Germany 4, Greece 7, & \\
& Italy 7, Netherlands 1, Portugal 1, & \\
& Spain 2, Sweden 1, Switzerland 1, & 39 \\
OCEANA: & Turkey 4, United Kingdom 1 & 3 \\
\hline \hline
\end{tabular}

that provide the real hope for astronomy in developing countries - and indeed everywhere.

Acknowledgments. His Holiness John Paul II is thanked for his support of the Schools, and all the VOSS faculty, staff and students are thanked for contributing their inspiration to this account.

\section{References}

Hearnshaw, J. B. 2001, this volume, p. 15-28.

Impey, C. 1999, in International Symposium on Astrophysics Research and Science Education, ed. C. Impey (Vatican Observatory Foundation), xi.

Joson, I. B., \& Aguirre, E. L. 2000, S\&T, 99, No.5, 82.

Maggio, E. J. 1997, The Vatican Observatory Summer Schools in Observational Astronomy and Astrophysics: The First Ten Years (Vatican Observatory Foundation).

Mahoney, T. J. 2001, this volume, p. 333-339.

Mattei, J. A., and Percy, J.R. 2001, this volume, p. 89-94.

Narlikar, J. V. 2001, this volume, p. 324-328.

Snowden, M. 2001, this volume, p. 266-275.

Rosenzweig, P. 2001, this volume, p. 205-209. 


\section{Discussion}

Hearnshaw commented that six graduate students from New Zealand had gone to VOSS and all had returned absolutely enthusiastic about the experience. He believed VOSS to be one of the best programs in the world for young astronomers. He wanted to know the topic for the 2001 school. Corbally thanked Hearnshaw for the graduate students he had sent, who had all brought much to the schools they attended. The 2001 school is to be on the theme "stellar remnants" - details on the website.

Kochhar suggested that another series of schools might be initiated dealing with topics such as those covered in this Special Session. Corbally said he would be delighted to consider it but the Observatory's manpower is limited. One year they ran a summer school for bishops (called a workshop) and had to skip a year in the sequence of student schools.

Snowden was puzzled that motivation was mentioned as one of the purposes of VOSS. First-year graduate students are surely already highly motivated. He also wondered if there were a clash of aims between the astronomers and the Vatican authorities. Corbally replied that, given the difficulties in the paths of many graduate students on their way to becoming full-tim researchers, they can well use a boost to their motivation at the VOSS and the continuing support that comes from the friendships made there. The Vatican authorities support astronomy as a value in itself. There is no clash between the Observatory staff and the Vatican over the schools. While this point of view may seem strange to some, its truth is contained in the Christian doctrine of the Incarnation.

Wentzel enquired how VOSS encouraged really useful letters of recommendation. Corbally said that this was done by getting the word out at meetings such as this and by responding honestly to queries why someone's brilliant student had not been selected. Alumnae of the schools, whether student or faculty, write particularly helpful letters. They know the kind of help needed in the difficult task of selection. 